\title{
The Spatial and Temporal Characteristics of Potential Evapotran- spiration in Sources Regions of Yangtze River Over the Past 55 Years
}

\author{
Chunmin Zhang ${ }^{1, a}$, Xunjian Long ${ }^{2, b}$ and Chuan Liang ${ }^{1, c}$ \\ ${ }^{1}$ College of water resource and Hydropower, Sichuan University, Chengdu 610065, China; \\ ${ }^{2}$ College of Resources and Environment, Southwest University, Chongqing 400715, China \\ achunminzhang@163.com, ${ }^{\mathrm{b}}$ Imcx402331@foxmail.com, ${ }^{\mathrm{c}}$ Ichesterlc@gmail.com
}

\begin{abstract}
Keywords: Potential evapotranspiration, spatial and temporal distribution, variation trend, sources
\end{abstract} regions of Yangtze River.

\begin{abstract}
Potential evapotranspiration is important to energy balance calculation and hydraulic cycle. And the value impacts water-heat balance obviously. Based on the theory of FAO Penman-Montieh equation, this manuscript taken the sources region of Yangtze River as a study case. For the calculation of Potential evapotranspiration from year 1960 to 2014, several conclusions can be summarized as follows: from the time series of calculation results, the variation trend of potential evapotranspiration in study area expressed as increase tendency, with the speed of $8.93 \mathrm{~mm}$ per decades. And the variation trends of seasonal scale in spring and autumn are greater than summer and winter. In addition, from the perspective of spatial variation, potential evapotranspiration shows evident relationship with hydrothermal condition. The reason is that potential evapotranspiration value in the regions with better hydrothermal conditions such as riverside were more than $700 \mathrm{~mm}$. however, the spatial distribution of increasing trend is from southeast to northwest. And the proof is that, changes in the east of Zhiduo-Qumalai are less than $4 \mathrm{~mm}$ per decades, but 8 to $16 \mathrm{~mm}$ per decades in the north of Tongtian River, especially in Beiluhe and Chumaer regions.
\end{abstract}

\section{Introduction}

Potential evapotranspiration is one of the most important principal elements of the hydrological cycle [1-3]. Theoretically, potential evapotranspiration which is the upper limit of evapotranspiration indicates the amount of water as the solid or liquid precipitation that reaches the earth's surface. Meanwhile, it is also the basic point on actual evapotranspiration. As a result, this indicator is widely used in wet and dry climate evaluation, water demand of agricultural crops, production management, and ecological environment research [4]. For China, these studies include, but are not limited to, temporal and spatial analysis of the sensitivity of potential evapotranspiration in China [5], reference crop evapotranspiration research in Plateau [6], evapotranspiration research on the upstream of Yellow River [7], the most sensitive meteorological factors acts on potential evapotranspiration in Yangtze River Basin [8].

Based on these reference studies, in order to discuss the Variation trend of potential evapotranspiration in the source of Yangtze River Basin, we collected several kinds of meteorological data from ground stations, such as maximum temperature, minimum temperature, average temperature, precipitation, wind speed, solar radiation, relative humidity, et.al.. And then we applied FAO Penman-Monteith method to Calculate monthly potential evapotranspiration of the Yangtze River source region from year1960 to 2014.evidently, this is a good attempt for hydraulic cycle influenced by climate change and water resource optimal allocation.

\section{Research Method}

\subsection{Study Area.}

The headwaters of the Yangtze River, located at $90^{\circ} \quad 43^{\prime}-96^{\circ} \quad 45^{\prime} \quad \mathrm{E}$ and $32^{\circ} 30^{\prime}-35^{\circ} 35^{\prime}$ $\mathrm{N}$, with an area of $13.78 \times 10^{4} \mathrm{~km}^{2}$, located in the interior of the Qinghai-Tibet plateau, was identified 
by Wang et al.. The geomorphology of this region is mainly dominated by tall hills and a well-developed network of watercourses, with an elevation of over $4000 \mathrm{~m}$. The headwaters area has a typical continental alpine cold and dry climate. Vegetation in the headwaters area is simple and dominated by alpine cold meadows and alpine steppe. In localized high-altitude zones, there are cushion plants and sparse talus plants. Soil in the source area is dominated by alpine meadow, alpine steppe, as well as some swamp meadow soils [9].

\subsection{Data.}

Data for precipitation, temperature and total solar radiation, synchronized, was provided by China Meteorological Data Sharing Service Network (http://cdc.cma.gov.cn/).

\subsection{Potential Evapotranspiration Calculation and Spatial Interpolation.}

Based on energy balance and aerodynamics theory, the FAO Penman-Monteith model is based on comprehensive theory and has been widely used. The equation is[10]:

$$
E T_{0}=\frac{0.408 \Delta\left(R_{n}-G\right)+\gamma \frac{900}{T_{a}+273} \mu_{2}\left(e_{s}-e_{a}\right)}{\Delta+\gamma\left(1+0.34 \mu_{2}\right)} .
$$

Where $E T_{0}$ is the reference crop evapotranspiration $(\mathrm{mm} / \mathrm{d}), \Delta$ is the slope of the saturation vapor pressure curve $\left(\mathrm{kPa} /{ }^{\circ} \mathrm{C}\right), R n$ is the net radiation at the surface $\left(\mathrm{MJ} /\left(\mathrm{m}^{2} \bullet \mathrm{d}\right)\right), G$ is the soil heat flux $\left(\mathrm{MJ} /\left(\mathrm{m}^{2} \bullet \mathrm{d}\right)\right), T$ is the average temperature $\left({ }^{\circ} \mathrm{C}\right), e_{s}$ is the saturation vapor pressure $(\mathrm{kPa}), e_{a}$ is the actual vapor pressure $(\mathrm{kPa}), \gamma$ is the psychometric constant $\left(\mathrm{kPa} /{ }^{\circ} \mathrm{C}\right), u_{2}$ is the wind speed at $2 \mathrm{~m}$ height $(\mathrm{m} / \mathrm{s})$.

In Tibet Plateau regions, the spatial distribution of temperature and rainfall is closely related to latitude, longitude, elevation and topography. Cheng et al. have summarized these characteristics in a three-dimensional zonal pattern [11]. In this study, regression analysis on climate data with longitude, latitude and altitude was conducted.

\subsection{Trend analysis.}

The rate of change is defined as the slope of the least-squares line fitting the annual variability of values over a specific time period. Similarly, a trend change can be calculated for a certain period and respective pixel by linear regression of one variable, $Y=a x+b$. Here, $x$ is the year number, and $Y$ is the value for each year. Eq. (2) can be used to calculate the slope of the linear time trend by OLS (Ordinary Least Squares) estimation.

$$
\text { Slope }=\frac{n \times \sum_{i=1}^{n} i \times y_{i}-\sum_{i=1}^{n} i \sum_{i=1}^{n} y_{i}}{n \times \sum_{i=1}^{n} i^{2}-\left(\sum_{i=1}^{n} i\right)^{2}} .
$$

Where $i$ represents year, from 1960 to 2014. Slope is the slope of the linear regression of the single variable equation. The total increase (or decrease) during the study period can be estimated for each pixel by Eq. (3).

$$
\text { Range }=\text { Slope } \times(n-1)
$$

\section{Results and discussion}

\subsection{Spatial distribution of $E T_{0}$.}

Fig. 1 is the spatial distribution map of potential evapotranspiration. From the distribution diagram, high values of potential evapotranspiration distributed in rivers, lakes and other area rich of water sources, such as Tongtian river, Tuotuohe, Muqu, Beiluhe, Chumaer, and Dangqu Basin. The average potential evapotranspiration of all these regions are greater than $700 \mathrm{~mm}$. evidently, these regions were classified to adequate moisture. Additionally, less potential evapotranspiration occupied in the high altitude mountainous regions, including Tanggula, Zuerkenwula and Kebaeren, because of rarely vegetation cover and poor soil. Therefore, we can layout hydraulic engineering to make full use of the limited water resources through the spatial distribution of $E T_{0 .}$. 


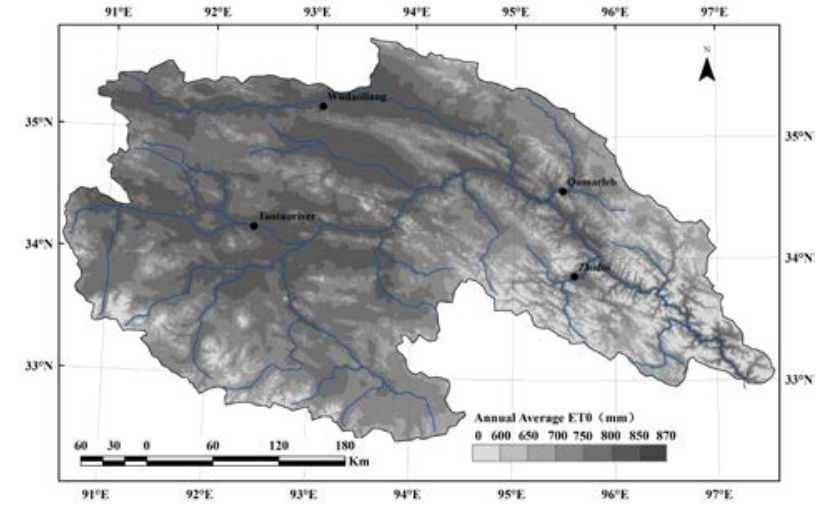

Fig. 1 Spatial distribution map of annual potential evapotranspiration ofYangtze River sources

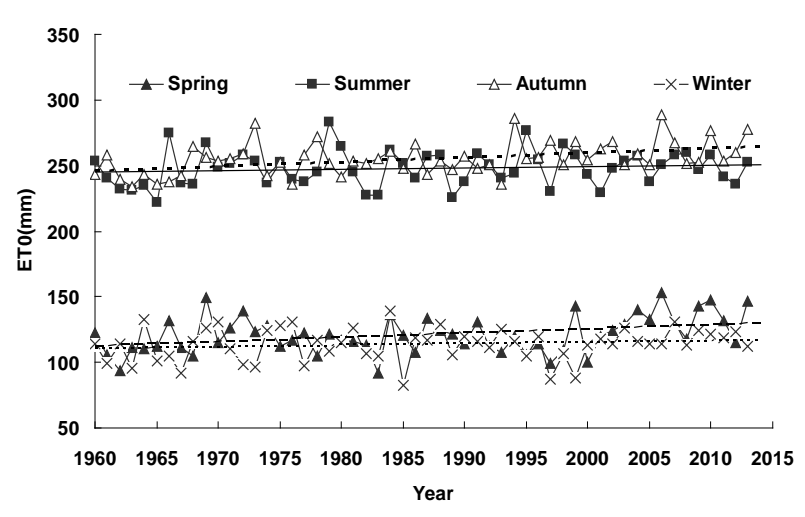

Fig.2 seasonal variation trend of potential evapotranspiration of Yangtze River sources

\subsection{Seasonal Variation of $E T_{0}$.}

The seasonal variation of $E T_{0}$ in selected station (Fig. 2) shows that within a year $E T_{0}$ is highest in autumn then in summer, and $E T_{0}$ is lowest in winter. The value of $E T_{0}$ in summer- autumn accounts for $71 \%$ of the total annual amount, while less than $30 \%$ in winter-spring. That is because $E T_{0}$ in study region is affected by the intensity of southeast monsoon airflow which makes water evaporation inhomogeneous, resulting in high evapotranspiration in summer- autumn and low evapotranspiration in winter. Meanwhile, as to increase range of the seasonal calculation results on $E T_{0}$, from the years 1960 to 2014, indicates that values in spring and autumn are greater than summer and winter.

\subsection{Annual Variation of $\boldsymbol{E} \boldsymbol{T}_{0}$.}

Table 1 and Fig. 3 show variation trend of potential evapotranspiration in the source region of Yangtze River from years 1960 to 2014. Generally speaking, during the calculation periods, there is an increasing variation trend with 8.93 per decades. The most evident variation period of $\mathrm{ET}_{0}$ trend and the annual variation of $\mathrm{ET}_{0}$ including three different periods that are 1960-1969, 1970-1997 and 1998-2014. However, $\mathrm{ET}_{0}$ shows increasing trend with $41.35 \mathrm{~mm} / 10 \mathrm{a}$, in period 1960-1969, decreasing trend with $9.2 \mathrm{~mm} / 10 \mathrm{a}$, in period 1970-1997 and increasing trend with $27.87 \mathrm{~mm} / 10 \mathrm{a}$, in period 1998-2014.

References are cited in the text just by square brackets [1]. (If square brackets are not available, slashes may be used instead, e.g. /2/.) Two or more references at a time may be put in one set of brackets $[3,4]$. The references are to be numbered in the order in which they are cited in the text and are to be listed at the end of the contribution under a heading References, see our example below.

Table 1 Change trend of $\mathrm{ET}_{0}$ for three different time periods in Source Region of Yangtze River

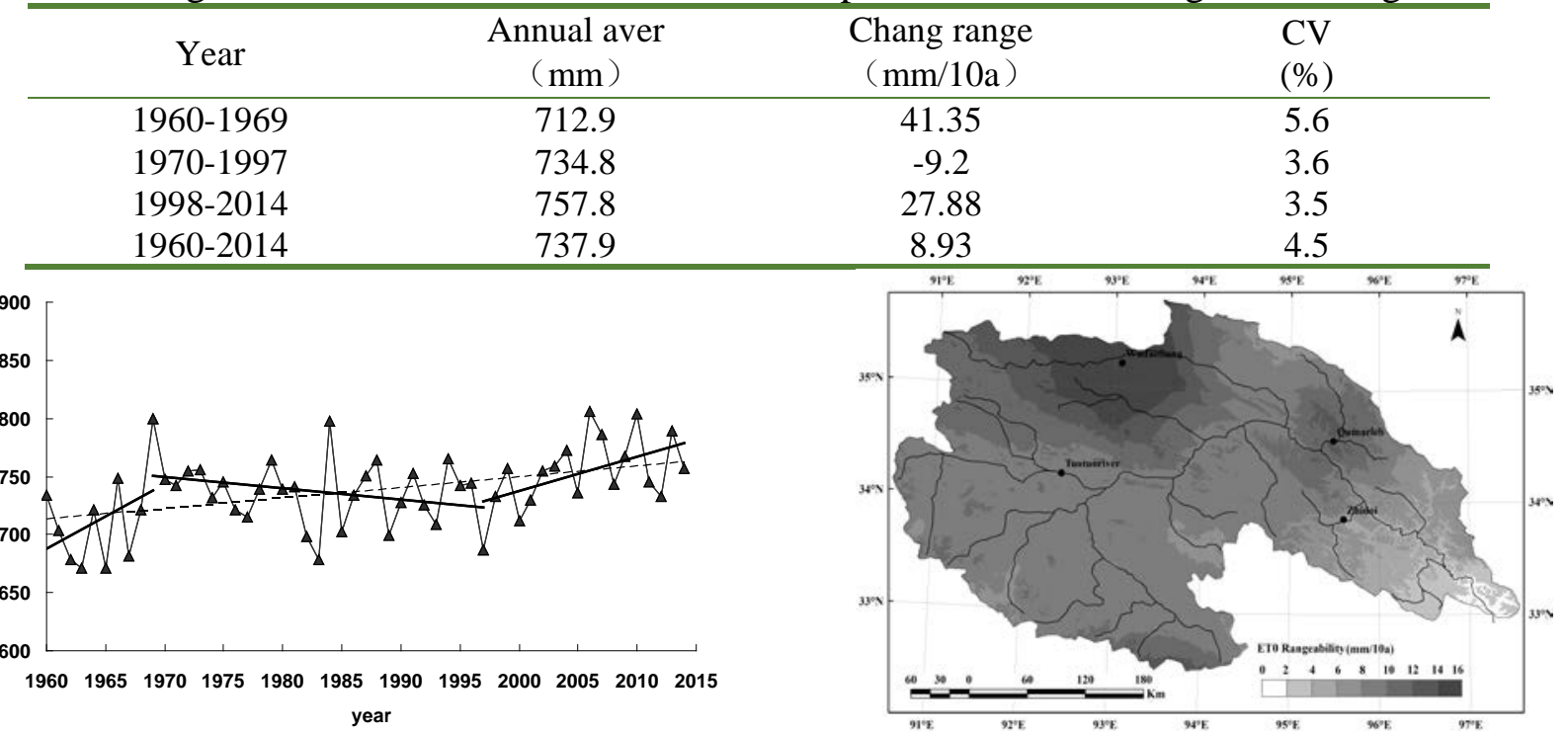

Fig. 3 Annual change and linear trend line of $E T_{0}$

Fig.4 spatial distribution of variation range 


\subsection{Spatial Distribution of Change Trend.}

Fig. 4 shows the spatial distribution of change trend. and the trend increased from southeast to northwest. Specific to the smaller area is that variation range with $4 \mathrm{~mm} / 10$ a occurred in the east of Zhiduo-Qumalai, 8mm/10a covered in the southern Tuotuo river -Tongtian River, and 8-16mm/10a happened in the northern Tongtian River, such as Beilu River, Chumaer River.

\section{Summary}

In this manuscript, taking the source regions of Yangtze River as the research object, based on the FAO Penman-Monteith model, potential evapotranspiration variation in nearly 55 years were calculated, and regression analysis on spatial and temporal variation of potential evapotranspiration were achieved. The results show that, during calculation periods, from year 1960 to 2014, annual potential evapotranspiration in the source regions of Yangtze River reflect an increasing trend, but non-uniform distribution. The results based on time scale display three significant periods, namely, years 1960 to 1969, years 1970 to 1997 and years 1998 to 2014. Regression analysis on climate data with longitude, latitude and altitude was conducted that highly variation regions appeared in north of Tongtian River, such as Beilu River and Chumaer River basin, and slower variation regions appeared in southern Tuotuo River and Tongtian River.

\section{Acknowledgements}

This study was funded by the Natural Science Foundation of China (No. 41271045), the National Basic Research Program of China (973, No. 2013CB036401), and Fundamental Research Funds for the Central Universities (SWU115081).

\section{References}

[1]. L.Q. Liang, L.J. Li, L. Zhang. Sensitivity of the reference crop evapotranspiration in growing season in the West Songnen Plain. Transactions of the CSAE. Vol. 24(2008), p. 1-5.

[2]. K. Parasuraman, A. Elshorbagy, S.K. Carey. Modelling the dynamics of the evapotranspiration process using genetic programming. Hydrological Sci. J. Vol. 52 (2000) No. 3, p. 563-578.

[3]. P.M. Lafleur. Connecting atmosphere and wetland: energy and water vapour exchange. Geography Compass. Vol. 2 (2008) No.4, p. 1027-1057.

[4]. M.Zhuo, P.X. Liu, Y.L. Zhang. Study on temporal and spatial changes of potential evapotranspiration and its impact factors in Loess plateau of Gansu Province. Research of soil and water conservation, Vol. 19 (2012) 70-76.

[5]. C.M. Liu, D. Zhang. Temporal and spatial change analysis of the sensitivity of potential evapotranspiration to meteorological Influencing factors in China. Acta Gegraphica sinica. Vol. 66(2011) No. 5, p. 579-588.

[6]. X. Liu, B. Chen. Climatic warming in the Tibetan Plateau during recent decades. Int. J. Climatol. Vol. 20 (2000) No. 14, p. 1729-1742.

[7]. X. Qiu, C. Liu, Y. Zeng. Changes of pan evaporation in the recent 40 years over the Yellow River Basin. Journal of Natural Resources. Vol. 18 (2003) No. 4, p. 437-442.

[8]. L.B. Gong, C.Y. Xu, D.L. Chen. Sensitivity of the Penman-Monteith reference evapotranspiration to key climatic variables in Changjiang (Yangtze River) Basin. Journal of Hydrology. Vol. 329 (2006) No. 3, p. 620-629.

[9]. G.X. Wang, Y.B. Wang, Y.S. Li. Influences of Alpine Ecosystem Responses to Climatic Change on Soil Properties on the Qinghai-Tibet Plateau, China. Catena. Vol. 70 (2007) No. 3, p. 506-514. 
[10]. R.G. Allen, L.S. Perreira, D. Raes. Crop evapotranspiration. FAO Irrigation and Drainage Paper 56. Roma, 1998.

[11]. G.D. Cheng, S.L. Wang. On the zonation of high-altitude permafrost in China. J. Glaciology \& Geocryology. Vol. 4 (1982) No. 2, p.1-17. 